\title{
Key Factors for Developing a Successful E-commerce Website
}

\author{
Osama Mohammed Ahmad Rababah and Fawaz Ahmad Masoud
}

\author{
The University of Jordan, Amman, Jordan
}

\begin{abstract}
The most experienced and successful E-commerce companies are beginning to realize that key determinants of success or failure are not merely a web presence or low price but delivering on a high quality website. To attain the desired quality of website software, it is necessary to produce a framework and model that enables evaluation of a website's quality. This paper defines and categorizes the quality factors for measuring an E-commerce website. The software is an essential part of the E-commerce website. The ISO 9126-1 standard for software engineering product quality states that the main purpose of software quality evaluation is to supply referential quantitative results for software products that are reliable, understandable and acceptable. According to Larsson (2004), quality factors are primarily attributes of the software that are often labeled as "non-functional requirements." The key challenge of these attributes is the lack of a formal specification of a means of measurement. This paper provides a framework to establish quality factors in terms of attributes, in addition to their level of importance based on the opinion of highly-skilled professionals. The primary goals are identifying, qualifying, categorizing and ranking these factors.
\end{abstract}

Keywords: E-commerce Website, Development, Quality, Evaluation

\section{Introduction}

The quality of a website is a property difficult to define and capture in an operational way, yet everybody feels it when it is missing. In fact, for a website there can be as many views of its quality as there are usages. Quality may depend on task-related factors affecting end users such as presentation quality and appeal, content and function adequacy, and navigability. It may also depend on performance-related factors that affect the efficiency of end users and the economics of the website within the company running it. These factors include response time, transaction throughput, reliability and robustness. It may depend on development-related factors that affect developers and maintainers of a website. These include code complexity, code readability, code flexibility, portability, page coupling and modifiability (Darie and Balanescu, 2008). The foundation model used to identifying quality factors and attributes is based on research by Albuquerque and Belchior (2002). The model is extended with further research

Copyright (C) 2010 Osama Mohammed Ahmad Rababah and Fawaz Ahmad Masoud This is an open access article distributed under the Creative Commons Attribution License unported 3.0, which permits unrestricted use, distribution, and reproduction in any medium, provided that original work is properly cited. Contact Author: Dr. Osama Mohammed Ahmad Rababah, e-mail: 0.Rababah@ju.edu.jo 
investigation and expert reviews and interviews.

Albuquerque and Belchior have organized a comprehensive set of software quality attributes into objectives where each objective is composed of a set of quality factors. Each quality factor is further decomposed into sub-factors. According to Albuquerque and Belchior (2002), three broad objectives formulate the model, as illustrated below which enables the evaluation of an E-commerce website's quality.

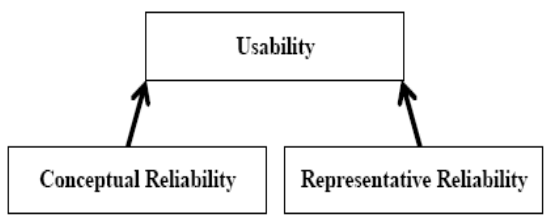

\section{Fig 1: E-commerce quality objectives}

Usability is a quality objective that refers to the characteristics that allow the use of the E-commerce site in the most diverse situations, not only during its development process, but also during its operation and maintenance. This objective builds on the reliability of the web site. Reliability is composed of two aspects, according to Albuquerque and Belchior (2002).

Conceptual reliability is concerned with the E-commerce site's capacity to implement, satisfactorily, what was specified and designed. Representative reliability refers to the E-commerce site's representation characteristics that affect its understanding and manipulation through its lifecycle (Cox and Dale, 2002). Albuquerque and Belchior's identification of the factors under these objectives was derived from their extensive questionnaires to both the user and developer communities in E-commerce.

\section{Identifying}

Further quality factors and attributes were researched to ensure having a comprehensive list of quality factors. In particular, scalability and availability were added as, according to Suh et al. (2009), E-commerce website software is large and complex, but quality requirements demand the key performance of factors such as availability, performance, scalability, and security. This, in essence, provides the biggest influence on the effective implementation of a website. Scalability is the website readiness to meet rising demands of users and usage. Thus, website software applications must be prepared to grow quickly both in terms of users serviced and in terms of services offered. According to Firesmith (2003), the need for scalability has been a driver for much of the technology innovations in the past few years. Industry has developed new software languages, new design strategies, and new communication and data transfer protocols, in part to allow web sites to grow as needed. According to Firesmith (2003), availability is of two parts. The first relates to the website accessibility and being up and running 24 hours a day, 7 days a week and 365 days a year. The second relates to the web software and it accessibility by diverse types of web browsers. Using the common denominator of features among all browsers as the baseline and removing any use of features unique to a particular browser ensures cross-browser availability. To be available in this sense requires significantly more knowledge and effort on the part of the software engineers. Table 1 lists the factors used with a short explanation of each factor. At this stage, and based on the academic 
research exercised, it was felt that a list of sixteen factors within three objectives satisfy an assessment of the quality of the operational software of an E-commerce website. The next step was to extend the factors with sub-factors that allow measurement to qualify the assessment. Table 2 displays the complete set of those quality attributes. They are a total of eighty four sub-factors organized within the quality factors.

\section{- Table 1: E-commerce Quality Factors -}

\begin{tabular}{|c|c|}
\hline \multicolumn{2}{|r|}{ Usability } \\
\hline Efficiency & The timeliness of which the website responds to the user. \\
\hline User-Friendliness & $\begin{array}{l}\text { The user interface capabilities to which the website provides a } \\
\text { supportive experience to the user. }\end{array}$ \\
\hline Navigability & The browsing extensibility which the website's software allows. \\
\hline Maintainability & $\begin{array}{l}\text { The reduced effort which the website's software requires for its } \\
\text { upkeep, enhancing its ability to be kept up to date and usable }\end{array}$ \\
\hline $\begin{array}{l}\text { Involvement } \\
\text { Capacity }\end{array}$ & $\begin{array}{l}\text { The measure of which the website can adapt to and attract each user's } \\
\text { individuality. }\end{array}$ \\
\hline \multicolumn{2}{|r|}{ Conceptual Reliability } \\
\hline Functionality & $\begin{array}{l}\text { The extent of the operational aspects of the website software and its } \\
\text { fitness of use. }\end{array}$ \\
\hline Security & $\begin{array}{l}\text { The extent of safety assured against malicious or accidental intrusion } \\
\text { of unauthorized users when using the website. }\end{array}$ \\
\hline Reliability & The extent of which the website remains available and working. \\
\hline Integrity & The reliability, consistency and correctness of stored data. \\
\hline Trustworthiness & $\begin{array}{l}\text { The extent to which the user perceives the website to behave } \\
\text { consistently, reliability and correctly, building a trusting relationship. }\end{array}$ \\
\hline Content Adequacy & $\begin{array}{l}\text { The extent to which the information presented is contextually } \\
\text { applicable to the user and sufficient for the user's needs. }\end{array}$ \\
\hline Scalability & The website readiness to meet rising demands in users and usage. \\
\hline Availability & $\begin{array}{l}\text { The extent of website accessibility to users through different browsers } \\
\text { in differing times. }\end{array}$ \\
\hline \multicolumn{2}{|r|}{ Representative Reliability } \\
\hline Readability & The appropriate application of the written language within the website \\
\hline $\begin{array}{l}\text { Standards } \\
\text { Conformance }\end{array}$ & $\begin{array}{l}\text { The extent of consistency applied within the user interface of the } \\
\text { website. }\end{array}$ \\
\hline $\begin{array}{l}\text { Ease Of } \\
\text { Manipulation }\end{array}$ & $\begin{array}{l}\text { The extent of help provided to operate the website and the software } \\
\text { underneath it. }\end{array}$ \\
\hline
\end{tabular}


- Table 2: Identified Quality Sub-Factors -

\begin{tabular}{|c|c|c|}
\hline \multicolumn{3}{|c|}{ Quality Sub-Factors } \\
\hline 1. Usability & 1.4.3 Analyzability & 2.5.2 Completeness \\
\hline 1.1 Efficiency & 1.4.4 Changeability & 2.5.3 Necessity \\
\hline 1.1.1 Time Behavior & 1.5 Involvement Capacity & 2.6 Content Adequacy \\
\hline 1.1.2 Purchase Process Performance & 1.5.1 Attractiveness & 2.6.1 Updated Content \\
\hline 1.1.3 Page Generation Speed & 1.5.2 Aesthetic Attributes & 2.6.2 Correctness \\
\hline 1.2 User-Friendliness & 1.5.3 Client Profile Identification & 2.6.3 Intelligibility \\
\hline 1.2.1 Understandability & 1.5.4 Simulation & 2.6.4 User Oriented \\
\hline 1.2.2 Products Information Availability & 1.5.5 Additional Services Availability & 2.6.5 Respectability \\
\hline 1.2.3 Interactivity & 2. Conceptual Reliability & 2.6.6 Concise Content \\
\hline 1.2.4 Learn-ability & 2.1 Functionality & 2.6.7 Completeness \\
\hline 1.2.5 Information Localizability & 2.1.1 Accuracy & 2.6.8 Compatibility With Real Store \\
\hline 1.2.6 Response Time Uniformity & 2.1.2 Client Support & 2.7 Scalability \\
\hline 1.2.7 Forms Of Payment Availability & 2.1.3 Information On Product Delivery & 2.7.1 Multiprocessor handling \\
\hline 1.2.8 Storage Of Purchase List & 2.1.4 Suitability & 2.7.2 Farming capabilities \\
\hline 1.2.9 Help Availability & 2.1.5 Flexibility & 2.8 Availability \\
\hline 1.2. 10 Products Comparison & 2.1.6 Interoperability & $2.8 .124 / 7 / 365$ Readiness \\
\hline 1.2.11 "Shopping Cart" Metaphor & 2.2 Security & 2.8.2 Partial Availability \\
\hline 1.2.12 Printing Facilities & 2.2.1 Payment Systems Security & 2.8.3 Browser version compatibility \\
\hline 1.2.13 Download Facilities & 2.2.2 Vulnerability & 2.8.4 Cross Browser Support \\
\hline 1.3 Navigability & 2.2.3 Site Authentication & 3. Representation Reliability \\
\hline 1.3.1 Absence Of Navigation Errors & 2.2.4 Access Control & 3.1 Readability \\
\hline 1.3.2 Minimal Path \& Shortcut Facility & 2.2.5 Confidentiality & 3.1.1 Language Correctness \\
\hline 1.3.3 Drawback & 2.2.6 Privacy & 3.1.2 Style Uniformity \\
\hline 1.3.4 Navigation Structure Taxonomy & 2.3 Reliabilitty & 3.1.3 Clarity \\
\hline 1.3.5 Links Visibility & 2.3.1 Recoverability & 3.1.4 Conciseness \\
\hline 1.3.6 Links Visualization Consistence & 2.3.2 Maturity & 3.1.5 Terminology Uniformity \\
\hline 1.3.7 Alternative Paths & 2.3.3 Fault Tolerance & 3.1.6 Abstraction Uniformity \\
\hline 1.3.8 Navigational Prediction & 2.4 Integrity & 3.2 Standards Conformance \\
\hline 1.3.9 User Level Adaptability & 2.4.1 Data Integrity & 3.2.1 Interface Standards \\
\hline 1.3.10 Interaction Storage Capacity & 2.4.2 Data Entry Signalizing & 3.2.2 Programming Standards \\
\hline 1.3.11 Mobile Devices Accessibility & 2.4.3 Robustness & 3.2.3 Navigation Standards \\
\hline 1.4 Maintainability & 2.4.4 Audit Trail & 3.3 Ease Of Manipulation \\
\hline 1.4.1 Stability & 2.5 Trustworthiness & 3.3.1 Up-To-Date \\
\hline 1.4.2 Testability & 2.5.1 Correctness & 3.3.2 Ability To Trace \\
\hline
\end{tabular}




\section{Qualifying}

To establish a rating system for the factors, a standard statistical rating scheme based on frequency of expert rating was used to reflect the relative importance of the different sub-factors within a factor (Wang, 2003). The weighting system was generated based on questionnaire results from expert specialists in E-commerce development and representative consumers of $\mathrm{E}$ commerce.

Participants in the questionnaires were selected based on meeting qualifying criteria. The qualifying criteria were derived from the industry best practices. The selection of the sampled participants was based on the following:

$\checkmark$ The number of E-commerce websites developed by the expert / respondent (at least 5websites to be considered).

$\checkmark$ The level of experience for each expert / respondent

$\checkmark$ The complexity and size of the developed E-commerce websites.

A total of twenty experts were surveyed from largest IT companies. The questionnaires were administered by the first researcher visiting these companies and interviewing the respondents. Each question gave the respondents the option to select one answer from multiple answers. Each answer was assigned a score from 0 to 7 depending on the question. The answers were recorded by the first researcher.

A score of 20 or above was used as the qualification to be considered as an expert (A score of 20 was chosen for convenience to get a range of experience of building websites with several different companies). The first researcher was able to define 13 experts/respondents out of
20 sampled, most of whom used to be software engineers and developers.

Once identified as an expert, the participants were asked to respond to the questionnaire that asked them to rate each of the sub-factors in order of importance of their contribution to the factor. The questionnaire also provides an explanation of how each sub-factor influences the factor it belongs to.

Initially, one randomly selected expert was identified for a pilot run to validate the content and style of the questionnaire. When the answers had been received from the pilot run, they were verified to make sure that the questions were clear, complete and unambiguous; the questionnaire was then distributed to the remaining twelve participants. Data generated from the pilot run was excluded from the final results.

$100 \%$ of the twelve respondents gave back their responses to the questionnaire. However, some of those who were given the questionnaire did not answer all parts of the questionnaire.

The questionnaire was administered during a face-to-face interview with the experts. For each interview engagement, an introduction orientation was given on the questionnaire followed by a one-onone question and answers session to gain the answers and clarified any ambiguities. The answers were recorded by the first researcher to assure accuracy and consistency, which follows the guidelines of the Delphi method. In general, the process of soliciting answers followed the standard Delphi method (Grisham, 2009) in soliciting expert opinions.

\section{Ranking}

The rating of sub-factors was done within each factor. The rating is sequentially based on the order of the importance of 
the sub-factors in their influence on the factor. So, for factor S having six subfactors of SS1 to SS6, each participant rated each sub-factor according to its importance in influencing $S$, where 1 was the most important and 6 was the least.

In handling missing values for subfactors, the average of received responses was calculated to fill in the gaps of missing observations. It was intended that sub-factors that had six or fewer responses would be removed from the analysis, but this did not prove to be necessary as each sub-factor had at least ten responses.

Once all results were collected, a weighting scheme was applied to reflect the relative importance (rating) of the different sub-factors based on the following formula: Sub-factor Percent Importance $=100-(\mathrm{M} / \mathrm{N}) * 100$ Where $\mathrm{M}$ represents the average rating received on a sub-factor and $\mathrm{N}$ represents the total number of sub-factors attributes for a given factor. The subtraction from 100 is to reverse the rating scale of the questionnaire so that the questionnaire rating of " 1 " has the highest percentage importance. The final rating achieved has the highest percentage given to the most important sub-factor, proceeding to the least important in a descending fashion.

\section{Results}

The final rating achieved has the highest percentage given to the most important sub-factor as the key factors to assessing the qualities of an E-commerce website, proceeding to the least important in a descending fashion. Table 3 shows the rating received by each sub factor.

- Table 3: Identified Quality Sub-Factors -

\begin{tabular}{|l|c|}
\hline Quality Sub-Factors & Rating \\
\hline Usability & \\
\hline Efficiency & 53 \\
\hline Time Behavior & 53 \\
\hline Page Generation Speed & 33 \\
\hline Purchase Process Performance & \\
\hline User-Friendliness & 76 \\
\hline Understandability & 74 \\
\hline Response Time Uniformity & 73 \\
\hline Interactivity & 68 \\
\hline Learn-ability & 52 \\
\hline Help Availability & 52 \\
\hline "Shopping Cart" Metaphor & 48 \\
\hline Products Comparison & 33 \\
\hline Forms Of Payment Availability & 27 \\
\hline Storage Of Purchase List & 26 \\
\hline Localizability & 26 \\
\hline Printing Facilities & 24 \\
\hline Download Facilities & 23 \\
\hline Products Information Availability & \\
\hline
\end{tabular}




\begin{tabular}{|c|c|}
\hline Quality Sub-Factors & Rating \\
\hline \multicolumn{2}{|l|}{ Navigability } \\
\hline Minimal Path \& Shortcut Facility & 80 \\
\hline Links Visibility & 72 \\
\hline Absence Of Navigation Errors & 67 \\
\hline Navigation Structure Taxonomy & 66 \\
\hline Links Visualization Consistence & 48 \\
\hline User Level Adaptability & 45 \\
\hline Interaction Storage Capacity & 29 \\
\hline Alternative Paths & 28 \\
\hline Navigational Prediction & 17 \\
\hline Mobile Devices Accessibility & 17 \\
\hline Drawback & 16 \\
\hline \multicolumn{2}{|l|}{ Maintainability } \\
\hline Stability & 60 \\
\hline Changeability & 52 \\
\hline Testability & 27 \\
\hline Analyzability & 10 \\
\hline \multicolumn{2}{|l|}{ Involvement Capacity } \\
\hline Attractiveness & 63 \\
\hline Client Profile Identification & 55 \\
\hline Aesthetic Attributes & 53 \\
\hline Simulation & 20 \\
\hline Additional Services Availability & 10 \\
\hline \multicolumn{2}{|l|}{ Conceptual Reliability } \\
\hline \multicolumn{2}{|l|}{ Functionality } \\
\hline Accuracy & 67 \\
\hline Suitability & 58 \\
\hline Client Support & 53 \\
\hline Information On Product Delivery & 44 \\
\hline Flexibility & 18 \\
\hline Interoperability & 10 \\
\hline \multicolumn{2}{|l|}{ Security } \\
\hline Payment Systems Security & 58 \\
\hline Site Authentication & 57 \\
\hline Access Control & 51 \\
\hline Privacy & 51 \\
\hline Confidentiality & 18 \\
\hline Vulnerability & 14 \\
\hline Reliability & \\
\hline
\end{tabular}




\begin{tabular}{|c|c|}
\hline Quality Sub-Factors & Rating \\
\hline Recoverability & 53 \\
\hline Fault Tolerance & 47 \\
\hline Maturity & 0 \\
\hline \multicolumn{2}{|l|}{ Integrity } \\
\hline Data Integrity & 58 \\
\hline Audit Trail & 25 \\
\hline Robustness & 22 \\
\hline \multicolumn{2}{|l|}{ Trustworthiness } \\
\hline Correctness & 50 \\
\hline Completeness & 0 \\
\hline \multicolumn{2}{|l|}{ Content Adequacy } \\
\hline Updated Content & 68 \\
\hline Correctness & 61 \\
\hline User Oriented & 55 \\
\hline Completeness & 52 \\
\hline Concise Content & 39 \\
\hline Intelligibility & 26 \\
\hline Respectability & 25 \\
\hline Compatibility With Real Store & 24 \\
\hline \multicolumn{2}{|l|}{ Scalability } \\
\hline Farming capabilities & 54 \\
\hline Multiprocessor handling & 21 \\
\hline \multicolumn{2}{|l|}{ Availability } \\
\hline Browser version compatibility & 57 \\
\hline 24/7/365 Readiness & 53 \\
\hline Cross Browser Support & 53 \\
\hline Partial Availability & 38 \\
\hline Notification Integrity & 13 \\
\hline \multicolumn{2}{|l|}{ Representation Reliability } \\
\hline \multicolumn{2}{|l|}{ Readability } \\
\hline Language Correctness & 75 \\
\hline Clarity & 67 \\
\hline Style Uniformity & 38 \\
\hline Conciseness & 33 \\
\hline Terminology Uniformity & 24 \\
\hline Abstraction Uniformity & 14 \\
\hline \multicolumn{2}{|l|}{ Standards Conformance } \\
\hline Interface Standards & 61 \\
\hline Programming Standards & 42 \\
\hline
\end{tabular}




\begin{tabular}{|l|c|}
\hline Quality Sub-Factors & Rating \\
\hline Navigation Standards & 31 \\
\hline Ease Of Manipulation & 44 \\
\hline Up-To-Date & 38 \\
\hline Ability To Trace & 35 \\
\hline Structure & 33 \\
\hline Documentation Availability & \\
\hline
\end{tabular}

\section{Conclusions}

This paper has determined the factors that assess the quality of an E-commerce website, identifying and rating the main quality attributes to this application domain. The list of attributes was derived from the specialized literature. The survey and analysis described in this paper enabled a greater understanding of the inter-relations and influences these sub-factors have on the main quality factors. The results provide an important foundation for the understanding of quality in E-commerce websites that will allow developers to assess the strengths and weaknesses of their sites in order to know where to focus further development to achieve the high quality needed for Ecommerce success.

\section{References:}

Albuquerque, A.B. and Belchior, A.D, (2002), 'E-commerce websites: a qualitative evaluation', Proceedings of the 11th International WWW Conference, Hawaii, ACM Press, pp. 294-300.

Cox, J. and Dale, B.G., (2002), 'Key quality factors in Web site design and use: An examination', International Journal of

Quality \& Reliability Management, Vol 19, No 7, pp. 862-888.
Darie, D and Balanescu, E, (2008), Beginning PHP and MySQL E-Commerce from Novice to Professional, Apress publisher.

Firesmith, D., (2003), 'Modern Requirements Specification', Journal of Object Technology, Vol. 2, No. 2: pp. 53-64.

Grisham.T, (2009), 'The Delphi technique: a method for testing complex and multifaceted topics', International Journal of Managing Projects in Business, Vol. 2, Issue 1, pp. 112-130.

ISO, 2001, ISO/IEC 9126-1, Software engineering - Product Quality - Part 1: Quality model.

Larsson, M. (2004), 'Predicting Quality Attributes in Component-based Software Systems', [Online] Available at: http://www.mrtc.mdh.se/index.phtml

Suh, W, Jongho, K, and Heeseok, L,( 2009), A Benchmarking-Based Requirement Analysis Methodology for Improving Web Sites, International Journal of Electronic Commerce / Spring 2009, Vol. 13, No. 3, pp. 119-162.

Wang, M., (2003), Assessment of EService Quality via E-Satisfaction in ECommerce Globalization, [Online] Available at: http://www.ejisdc.org/ojs2/index.php/ej isdc/article/viewFile/68/68 